\title{
ANALISIS RENCANA ANGGARAN BIAYA PENGGUNAAN ALAT BERAT SHEEP'S FOOT ROLLER DAN VIBRATOR ROLLER DALAM PEKERJAAN BADAN JALAN PADA PROYEK PEMBANGUNAN JALAN TOL MEDAN- KUALANAMU- TEBING TINGGI SEKSI 3: PARBARAKAN - LUBUK PAKAM ZONA 5
}

\author{
Indah Siahaan ${ }^{1}$, Edim Sinuraya ${ }^{2}$ \\ ${ }^{1}$ Alumni Program Studi D3 Teknik Sipil, Fakultas Teknik UNIMED \\ ${ }^{2}$ Dosen Pengajar Jurusan Pendidikan Teknik Bangunan, Fakultas Teknik UNIMED \\ (edimsinuraya@gmail.com)
}

\begin{abstract}
ABSTRAK
Penelitian ini bertujuan untuk mengetahui produktivitas dan renana anggaran biaya yang dibutuhkan untuk penggunaan alat berat sheep foot roller dan vibrator roller dalam pekerjaan pekerjaan badan jalan pada proyek pembangunan jalan tol Medan- Kualanamu- Tebing Tinggi Seksi 3: Perbarakan- Lubuk Pakam (zona 5). Dalam teknik pelaksanaan pekerjaan badan jalan pada proyek pembangunan jalan tol Medan- Kualanamu Tebing Tinggi Seksi 3: Perbarakan- Lubuk Pakam (zona 5) sudah sesuai dengan standard SNI. Dalam penyelesaian penelitian ini, penulis mencoba menghitung produktivitas dan rencana anggaran biaya yang diperlukan dalam pekerjaan badan jalan pada proyek pembangunan jalan tol Medan- Kualanamu- Tebing Tinggi Seksi 3: Perbarakan- Lubuk Pakam (zona 5).
\end{abstract}

Kata Kunci : rencana anggaran biaya, Sheep foot roller, Vibrator roller Pekerjaan Pemadatan Badan Jalan

\begin{abstract}
This research aims to determine the productivity and renana budget required for the use of heavy equipment and a vibrator roller sheep foot roller in the work of the agency's work on highway construction projects KualanamuMedan-Tebing Tinggi Section 3: Perbarakan-Lubukpakam (zone 5). In the technical implementation of the work of the road on highway construction projects Tebing Tinggi Medan-Kuala Namu Section 3: PerbarakanLubukpakam (Zone 5) is in conformity with ISO standards. In the completion of this study, the authors tried to calculate productivity and the budget plan is required in the work of the road on highway construction projects Kualanamu-Medan-Tebing Tinggi Section 3: Perbarakan-Lubukpakam (zone 5).
\end{abstract}

Keywords: the budget plan, Sheep foot roller, roller Vibrator Compaction Works Agency for Roads

\section{Pendahuluan}

Perkembangan pembangunan di Indonesia yang saat ini sedang dilakukan diberbagai provinsi di Indonesia sangatlah berpengaruh untuk kemajuan Negara Indonesia ini nantinya. Salah satunya di Provins i Sumatera Utara yaitu pada proyek pembangunan jalan tol yang termasuk dalam suatu proyek yang cukup besar dan banyak menyerap tenaga kerja.

Suatu proyek konstruksi akan berhasil karena adanya perencanaan dan pelaksanaan yang baik di lapangan. Pada proyek konstruksi bangunan jalan khususnya jalan tol sangat diperlukan adanya perencanaan yang nantinya akan dipakai untuk menjadi acuan pada saat berada di lapangan. Perencanaan dibuat bertujuan agar semua pekerjaan yang dilakukan dalam proyek dapat terkoordinasi dan berjalan dengan baik.

Pada saat ini hampir semua proyek bangunan seperti proyek pembangunan rumah tempat tinggal, proyek pembangunan jembatan, proyek pembangunan jalan tol, semua sudah diatur oleh sistem manajemen yang nantinya akan mengatur semua pelaksanaan pekerjaan dalam proyek agar dapat berjalan dengan baik dan teratur. 
Rencana Anggaran Biaya adalah salah satu dari bagian sistem manajemen dalam proyek yang sangat berpengaruh dalam pelaksanaan proyek. Alat berat adalah peralatan yang sangat diperlukan untuk membantu pekerjaan dalam proyek. Penggunaan alat berat bukan hanya dipakai begitu saja. Alat berat dalam proyek juga diatur dalam manajemenan ggaran biaya proyek agar penggunaannya teratur.

Alat berat Sheep's foot Roller dan Vibrator Roller dalam sebuah proyek konstruksi jalan sangat penting untuk digunakan yaitu dalam proses pembuatan atau pekerjaan badan jalan. Pada pekerjaan badan jalan ini yang meliputi bagian penggunaan Sheep's foot Roller dan Vibrator Roller adalah pekerjaan bagian timbunan untuk pembentukan badan jalan.

Sheep's foot Roller danVibrator Roller sangat berperan penting dalam pekerjaan badan jalan, dimana fungsi dari kedua alat ini hampir sama yaitu untuk memadatkan timbunan dan membantu mengurangi kadar air di dalam tanah.

\section{Identifikasi Masalah}

Berdasarkan latar belakang di atas adapun permasalahan yang ditinjau dalam proyek pekerjaan badan jalan, jalan tol MedanKualanamu- Tebing Tinggi adalah Rencana Anggaran Biaya penggunaan alat berat sheep foot roller dan vibrator roller dimana peranan alat berat menunjukkan kelancaran bagi suatu proyek konstruksi, sehingga perlu diteliti bagaimana rencana anggaran biaya penggunaan alat berat sheep foot roller dan vibrator roller dalam pekerjaan badan jalan, jalan tol Medan- Kualanamu- Tebing Tinggi.

a. Alat-alat berat apa sajakah yang digunakan pada proyek pekerjaan badan jalan.

b. Bagaimanakah produktivitas alat-alat berat yang digunakan.

c. Rencana Anggaran Biaya penggunaan alatalat berat.

\section{BatasanMasalah}

Berdasarkan identifikasi masalah maka batasan masalah dalam penulisan ini adalah menganalisis rencana anggaran biaya penggunaan alat berat sheep foot roller dan vibrator roller dalam pekerjaan badan jalan pada proyek pembangunan jalan tol MedanKualanamu- Tebing Tinggi, dimana penulis mengamati pekerjaan badan jalan dan pegadaan material dan perataan pada seksi 3: Perbarakan- LubukPakam, yaitu pada zona 5.

\section{Rumusan Masalah}

Berdasarkan identifikasi masalah dan batasan masalah yang telah diuraikan di atas, maka rumusan masalah adalah sebagai berikut

a. Bagaimana produktivitas alat berat Sheep Foot Roller dan Vibrator Roller?

b. Bagaimana produktivitas dan biaya pengunaan alat berat Sheep Foot Roller dan Vibrator Roller?

c. Bagaimana perhitungan anggaran biaya penggunaan alat berat Sheep Foot Roller dan Vibrator Roller?

\section{Tujuan Penulisan}

a. Untuk mengetahui produktivitas alat berat Sheep Foot Roller dan Vibrator Roller pada proyek pembangunan jalan tol MedanKualanamu- Tebing Tinggi.

b. Mengetahui produktivitas dan biaya pengunaan alat berat Sheep Foot Roller dan Vibrator Roller pada proyek pembangunan jalan tol Medan- Kualanamu- Tebing Tinggi.

c. Untuk mengetahui perhitungan penggunaan alat berat Sheep Foot Roller dan Vibrator Roller dan analisis Rencana Anggaran Biaya Sheep Foot Roller dan Vibrator Roller pada zona 5.

\section{Metode Pengumpulan Data}

a. Melakukan pengamatan langsung ke proyek pembangunan jalan Tol MedanKualanamu- Tebing Tinggi Seksi 3: Perbarakan- Lubuk Pakam, yaitu pada zona 5.

b. Studi perpustakaan yaitu pengumpulan informasi- informasi dari buku literatur atau materi-materi yang berhubungan dengan judul Penelitian ini dari berbagai sumber seperti buku, internet, dan jurnal.

c. Konsultasi dengan yang bertugas pada proyek pembangunan jalan tol MedanKualanamu- Tebing Tinggi.

\section{Kajian Teori}

Pada suatu proyek konstruksi peranan alat berat sangatlah diperlukan dalam membantu setiap bagian- bagian pekerjaan yang ada dalam proyek tersebut dengan skala besar.

Analisis biaya adalah suatu cara perhitungan harga satuan pekerjaan yang 


\section{Analisis Rencana Anggaran Biaya Penggunaan Alat Berat Sheep's Foot Roller Dan Vibrator Roller Dalam Pekerjaan Badan Jalan Pada Proyek Pembangunan Jalan Tol Medan- Kualanamu- Tebing Tinggi Seksi 3: Parbarakan - Lubuk Pakam Zona 5}

dijabarkan dalam perkalian indeks alat yang digunakan dan upah kerja dengan harga sewa peralatan dan standar pengupahan pekerja, untuk menyelesaikan per-satuan pekerjaan.

\section{Pekerjaan Badan Jalan}

Pekerjaan badan jalan adalah penyiapan badan jalan pada pekerjaan jalan dan pelebaran jalan yang meliputi pekerjaan pembersihan, pembentukkan tanah dasar dan pembentukkan elevasi jalan agar elevasinya sesuai dengan yang ditunjukkan gambar rencana atau sesuai dengann petunjuk direksi pekerjaan, dan termasuk pekerjaan pemadatan tanah dasar.

\section{Pekerjaan Persiapan}

Adapun pekerjaan-pekerjaan yang dilaksanakan dalam pekerjaan persiapan tersebut, yaitu :

a. Pekerjaan pematokan dan pengukuran ulangPekerjaan pematokan dan pengukuran ulang dilaksanakan oleh kontraktor pelaksana dengan tujuan pengecekan ulang pengukuran. Pemasangan patok pengukuran untuk profil memanjang dipasang pada setiap jarak 25 meter.

b. Survey kelayakan struktural konstruksi perkerasan.Kelayakan struktural konstruksi perkerasan dilaksanakan dengan pemeriksaan destruktif yaitu suatu cara pemeriksaan dengan menggunakan alat DCP (Dinamic Cone Penetrometer) untuk mengetahui nilai CBR (California Bearing Ratio).

c. Penyiapan badan jalan Pekerjaan ini meliputi pembersihan lokasi, penutupan jalan dan lainnya. Sehingga pelaksanaan proyek ini berjalan dengan lancar.

\section{Pekerjaan Galian}

Adapun prosedur pekerjaan dari pekerjaan galian, yaitu :

a. Lokasi yang akan dipotong (cutting) haruslah terlebih dahulu dilakukan pekerjaan clearing dan grubbing yang bertujuan untuk membersihkan lokasi dari akar-akar pohon dan batu-batuan.

b. Untuk mengetahui elevasi jalan rencana, surveyor harus melakukan pengukuran dengan menggunakan alat ukur (theodolit). Apabila elevasi tanah tidak sesuai maka tanah dipotong kembali dengan menggunakan alat berat (motor grader), sehingga merata sampai elevasi yang diinginkan.

c. Memadatkan tanah yang telah dipotong dengan menggunakanSheep's Foot Roller dan Vibrator Roller.

d. Melakukan pengujian kepadatan tanah dengan tes kepadatan (ujidensity Sand Cone test) di lapangan.

\section{Pekerjaan Timbunan}

Timbunan tanah yang dilakukan pada pekerjaan tanah biasanya diberi persyaratan kepadatan. Oleh karena itu pekerjaan timbunan pada dasarnya adalah pekerjaan pemadatan tanah.

\section{Pekerjaan Pemadatan}

Pemadatan tanah adalah suatu proses dimana udara pada pori-pori tanah dikeluarkan dengan cara mekanis.Standar kepadatan menggunakan ukuran standar proktor (misalnya 95\% standar proktor). Cara pemadatan tanah yang perlu diperhatikan adalah :

a. Pemberian air untuk pemadatan secukupnya.

b. Pemadatan dilakukan lapis demi lapis dengan ketebalan gembur (loose), tertentu (maks. $25 \mathrm{~cm}$ per lapis), tergantung besarnya energi alat pemadatan yang bersangkutan.

c. Untuk menetapkan tebal lapisan gembur, dan berapa kali lintasan pemadatan dengan alat yang ada.

d. Pemilihan jenis alat pemadatan yang sesuai dengan jenis tanah yang akan dipadatkan.

\section{Pengujian Kepadatan Tanah/ Sand Cone}

Pengujian ini bertujuan untuk mengetahui nilai kepadatan dan kadar air dilapangan. Juga bisa sebagai perbandingan pekerjaan yang akan dilaksanakan dilapangan dengan perencanaan pekerjaan.

\section{Alat Berat}

Menurut Rostiyanti (2002) : (1) yang dimaksud dengan alat- alat berat yang dikenal di dalam ilmu Teknik Sipil adalah alat yang digunakan untuk membantu manusia dalam melakukan pekerjaan pembangunan suatu struktur. Tujuan dari penggunaan alat-alat 
berat tersebut adalah untuk memudahkan manusia dalam mengerjakan pekerjaannya, sehingga hasil yang diharapkan dapat tercapai dengan lebih mudah dengan waktu yang relatif lebih singkat.

Tabel 1. Alat pemadat yang cocok untuk jenis tanah tertentu

\begin{tabular}{|c|c|c|c|c|c|}
\hline Material & $\begin{array}{l}\text { Steel } \\
\text { Whe } \\
\text { el }\end{array}$ & $\begin{array}{l}\text { Pneum } \\
\text { atic }\end{array}$ & $\begin{array}{l}\text { Vibrat } \\
\text { ory }\end{array}$ & $\begin{array}{l}\text { Tampi } \\
\text { ng } \\
\text { Foot }\end{array}$ & $\begin{array}{l}\text { Gri } \\
\text { d }\end{array}$ \\
\hline Batuan & 1 & 3 & 1 & 1 & 1 \\
\hline $\begin{array}{l}\text { Kerikil, } \\
\text { Bersih } \\
\text { atau } \\
\text { berlump } \\
\text { ur }\end{array}$ & 1 & 2 & 1 & 1 & 1 \\
\hline $\begin{array}{l}\text { Kerikil } \\
\text { berlemp } \\
\text { ung }\end{array}$ & 1 & 2 & 2 & 1 & 2 \\
\hline $\begin{array}{l}\text { Pasir, } \\
\text { bersih } \\
\text { atau } \\
\text { berlump } \\
\text { ur }\end{array}$ & 3 & 3 & 1 & 3 & 2 \\
\hline $\begin{array}{l}\text { Pasir, } \\
\text { berlemp } \\
\text { ung }\end{array}$ & 3 & 2 & 2 & 1 & 3 \\
\hline $\begin{array}{l}\text { Lempun } \\
\mathrm{g} \\
\text { berpasir } \\
\text { atau } \\
\text { berlump } \\
\text { ur }\end{array}$ & 3 & 1 & 2 & 1 & 3 \\
\hline $\begin{array}{l}\text { Lempun } \\
\mathrm{g} \text {, berat }\end{array}$ & 3 & 1 & 2 & 1 & 3 \\
\hline
\end{tabular}

Keterangan : 1 = direkomendasikan

2 = dapat dipakai

3 = kurang direkomendasikan

(sumber :Construction Methods and Management, 1998, dalam Rostiyanti (2002)

\section{Alat Berat Sheep Foot Roller}

Prinsip dari sheep's foot roller ini adalah sebuah silinder yang dibagian luarnya dipasang kaki-kai, pada kaki-kai ini terjadi tekanan yang tinggi, sehingga kaki-kaki ini baik digunakan untuk tanah berpasir dengan sedikit mengandung lempung juga tanah yang plastis dan kohesif.

Rumus Produktivitas sheep foot roller:

$$
\mathbf{K P}=\frac{\mathrm{LK} \times \mathrm{F} \times \mathrm{H} \times 1000 \times \mathrm{FK}}{\mathrm{N}} \mathrm{m}^{3} / \mathrm{jam}
$$

Dimana :

$\mathrm{KP}=$ Taksiran kapasitas produksi $\left(\mathrm{m}^{3} / \mathrm{jam}\right)$
LK = Lebar efektif drum (m)

$\mathrm{F} \quad=$ Kecepatan kerja $(\mathrm{km} / \mathrm{jam})$

$\mathrm{H}=$ Ketebalan material yang dipadatkan untuk setiap jalur pemadatan (m)

$\mathrm{N}=$ Jumlah passing

FK $=$ Faktor koreksi, terdiri dari :

- efisisiensi waktu

- efisiensi kerja

- efisiensi operator

\section{Alat Berat Vibrator Roller}

Vibrator roller adalah alat yang digunakan untuk pemadatan tanah atau material sedemikian hingga tercapai tingkat kepadatan yang diinginkan.Jenis rodanya biasanya terbuat dari besi seluruhnya atau ditambah dengan pemberat berupa air atau pasir.Bisa terbuat dari karet berupa roda ban.

Rumus produktivitas vibrator roller:

$$
K P=\frac{L K \times F \times H \times 1000 \times F K}{N} \mathrm{~m}^{3} / j a m
$$

Dimana :

$\mathrm{KP}=$ Taksiran kapasitas produksi $\left(\mathrm{m}^{3} / \mathrm{jam}\right)$

LK = Lebar efektif drum (m)

$\mathrm{F} \quad=$ Kecepatan kerja $(\mathrm{km} / \mathrm{jam})$

$\mathrm{H}=$ Ketebalan material yang dipadatkan untuk setiap jalur pemadatan (m)

$\mathrm{N}=$ Jumlah passing

FK = Faktor koreksi, terdiri dari :

- efisisiensi waktu

- efisiensi kerja

- efisiensi operator

\section{Dump Truck}

Pada pelaksanaan pekerjaan untuk pengangkutan tanah material timbunan dipergunakan alat berat Dump Truck.Dump Truck sangat baik digunakan untuk pengangkutan tanah yang relatif jarak angkut cukup jauh.

Berikut rumus kapasitas produksi Dump Truck:

$$
\text { Q Dump Truck }=\text { Kapasitasx } \frac{60}{C T} x \text { efisiensi }
$$

Dimana :

$$
\begin{aligned}
& \mathrm{Q}=\text { Produktivitas (jam) } \\
& \mathrm{CT}=\text { Waktu Siklus (menit) }
\end{aligned}
$$

\section{Motor Grader}

Pada pelaksanaan pekerjaan untuk pembentukan permukaan (perataan) digunakan alat berat Motor Grader juga untuk 


\section{Analisis Rencana Anggaran Biaya Penggunaan Alat Berat Sheep's Foot Roller Dan Vibrator Roller Dalam Pekerjaan Badan Jalan Pada Proyek Pembangunan Jalan Tol Medan- Kualanamu- Tebing Tinggi Seksi 3: Parbarakan - Lubuk Pakam Zona 5}

membentuk

permukaan yang

dikehendaki.Penggunaan alat berat ini sangat tepat karena bekerja sangat kuat, cepat dan praktis.

Berikut kapasitas produksi motor grader :

$$
\text { Prod }=1000 \mathrm{vWE}
$$

Dimana :

$$
\begin{aligned}
& \mathrm{V}=\text { Kecepatan alat }(\mathrm{km} / \mathrm{jam}) \\
& \mathrm{W}=\text { Lebar efektif per pass (meter) } \\
& \mathrm{E}=\text { Efisiensi Kerja alat }
\end{aligned}
$$

\section{Rencana Biaya Operasional Alat Berat}

Biaya-biaya yang termasuk biaya pengeluaran alat berat adalah biaya penyewaan alat, biaya mobilisasi dan demobilisasi, dan biaya upah tenaga operator. Peralatan konstruksi yang digerakan oleh motor bakar (internal combustion engine) memerlukan solar dan minyak pelumas, yang juga harus diperhitungkan sebagai biaya operasional.

\section{Biaya Penyewaan Alat}

Tidak semua peralatan konstruksi dimiliki oleh kontraktor. Dalam menyelesaikan pekerjaan-pekerjaan tertentu, diperlukan peralatan-peralatan khusus yang diperoleh dengan cara menyewa.

\section{Biaya Bahan Bakar}

Jumlah bahan bakar untuk alat berat yang menggunakan bensin atau solar berbedabeda.

$$
\text { Bensin : } \mathrm{BBM}=0,06 \times \mathrm{HP} \times \text { eff }
$$$$
\text { Solar : } \mathrm{BBM}=0,04 \times \mathrm{HP} \times \mathrm{eff}
$$

\section{Biaya Upah Kerja}

Besarnya upah kerja untuk operator/ helper pada excavator, bulldozer, motor grader, vibrator roller dan sopir/kenek pada dump truck adalah tergantung dari lokasi pekerjaan, perusahaan yang bersangkutan, peraturan yang berlaku di lokasi, dan kontrak kerja antara dua pihak tersebut.

\section{Perhitungan Pemakaian Minyak Pelumas}

Perhitungan penggunaan pelumas per jam (Qp) biasanya berdasarkan jumlah waktu operasi dan lamanya penggantian pelumas. Pergantian minyak pelumas dilakukan setiap 100 sampai 200 jam, dapat dihitung jika diketahui daya mesin (hp), kapasitas karter (c), selang penggantian ( $\mathrm{t}$ ) dan faktor efisiensi alat (f).

$$
\mathrm{Qp}=\frac{f x H p x 0,06}{7,4}+\frac{c}{t}
$$

\section{Biaya Mobilisasi dan Demobilisasi}

Alat berat yang disewa dari suatu tempat, membutuhkan biaya transportasi alat tersebut ke lokasi proyek dan biaya transportasi alat tersebut kembali ketempat asalnya.Untuk alat-alat berat tertentu bahkan diperlukan kendaraan khusus untuk mengangkat alat berat tersebut ke lokasi proyek dan sebaliknya.

\section{Biaya Operasional Total}

Biaya operasional total yang dikeluarkan untuk masing-masing tipe alat adalah penjumlahan semua biaya yang dikeluarkan untuk penyewaan alat, upah tenaga operator dan biaya untuk pemakaiaan solar dan minyak pelumas selama waktu pelaksanaan pekerjaan

\begin{tabular}{|c|c|c|c|c|}
\hline No & $\begin{array}{l}\text { Jenis } \\
\text { pekerjaan } \\
\text { / Jenis } \\
\text { Biaya }\end{array}$ & Vol & $\begin{array}{l}\text { Harga } \\
\text { Satuan }\end{array}$ & Biaya \\
\hline 1 & $\begin{array}{l}\text { Biaya } \\
\text { penyewaan } \\
\text { alat }\end{array}$ & & & \\
\hline 2 & $\begin{array}{l}\text { Biaya } \\
\text { Bahan } \\
\text { Bakar }\end{array}$ & & & \\
\hline 3 & $\begin{array}{l}\text { Biaya Upah } \\
\text { kerja }\end{array}$ & & & \\
\hline 4 & $\begin{array}{l}\text { Biaya } \\
\text { pemakaian } \\
\text { minyak } \\
\text { pelumas }\end{array}$ & & & \\
\hline 5 & $\begin{array}{l}\text { Biaya } \\
\text { Pemakaian } \\
\text { Gemuk }\end{array}$ & & & \\
\hline
\end{tabular}
ditambah biaya mobilisasi dan demobilisasi alat. Biaya operasional total alat ditulis dengan variabel Co dengan satuan rupiah.

Tabel 2. Rencana Anggaran Biaya (RAB) (Biaya Operasional Total)

\section{Analisis Harga Satuan}

Analisis harga satuan pekerjaan merupakan analisis material, upah tenaga kerja, dan peralatan untuk membuat satuan-satuan pekerjaan tertentu yang diatur dalam SNI 
maupun BOW.Dari hasilnya ditetapkan koefisien pengali untuk material, upah tenaga kerja dan peralatan semua jenis pekerjaan.Sedangkan analisis di lapangan ditetapkan berdasarkan hasil perhitungan di lapangan.

\section{Analisis Rencna Anggaran Biaya dan Pembahasan \\ Berdasarkan hasil penelitian yang} ditinjau dari lapangan dengan adanya teknik pelaksanaan pekerjaan badan jalan dan rencana anggaran biaya penggunaan alat berat sheep foot roller dan vibrator roller yang dipakai dalam proyek pembangunan jalan tol MedanKualanamu - Tebing Tinggi seksi 3: Perbarakan- Lubuk Pakam pada zona 5 dengan panjang $600 \mathrm{~m}$ dan lebar $30 \mathrm{~m}$, penelitian ini meninjau, terdiri dari :

\section{Pekerjaan Persiapan}

a) Pengujian CBR (California Bearing Ratio) pada tanah dasar mengunakan alat uji DCP (Dinamic Cone Penetrometer), dengan syarat $\geq 6 \%$.Tujuannya adalah untuk mengetahui daya dukung tanah.

b) Pekerjaan pematokan dan pengukuran dengan tujuan pengecekan ulang pengukuran. Pemasangan patok pengukuran untuk profil memanjang yang pada proyek ini dipasang pada setiap jarak 25 meter.

c) Pembersihan lokasi pekerjaan atau pekerjaan galian biasa dengan menggali tanah berlumpur, sampah, atau bahan tak terpakai lainnya sampai kedalaman yang diminta oleh Konsultan Pengawas dan menutup jalan, sehingga pelaksanaan pekerjaan timbunan berjalan dengan lancar.

\section{Proses Penghamparan}

a) Sebelum memulai pekerjaan timbunan badan jalan, Kontraktor terlebih dahulu mengurug kembali segala lubang dan memadatkannya hingga mencapai kepadatan $95 \%$ kepadatan kering maksimum atau dalam proyek pembangunan jalan tol Medan- KualanamuTebing Tinggi memakai standard sesuai AASHTO T99.

b) Borrow material atau material timbunan badan jalan dihampar selapis demi selapis atau per layer horizontal dengan tebal yang sama yaitu $25 \mathrm{~cm} /$ layer dalam keadaan padat dengan panjang $100 \mathrm{~m} /$ sisi jalan.

\section{Proses Pemadatan}

Pada tahap ini tanah laterit/ tanah merah yang telah dihamparkan kemudian dipadatkan agar mendapatkan ketebalan sesuai dengan yang direncanakan. Pada bagian ini alat berat yang digunakan ada 2 (dua) jenis yaitu :Sheep Foot Roller dan Vibrator Roller dimana pada tahap yang pertama alat berat yang digunakan adalah Sheep Foot Roller dengan banyak passing/ lintasan sebanyak 4 (empat) passing dengan tebal lapisan $25 \mathrm{~cm} /$ layer, dan pada tahap yang ke 2 digunakan alat berat Vibrator Roller dengan banyak passing/lintasan rencana sebanyak 8 passing dengan tebal lapisan 25 $\mathrm{cm} /$ layer.

\section{Sheep Foot Roller dan Produktivitasnya}

$$
\begin{aligned}
\mathrm{KP} & =\frac{1,60 \times 2,50 \times 0,25 \times 1000 \times 0,83}{4} \mathrm{~m}^{3} / \mathrm{jam} \\
& =\frac{830}{4} \\
& =207,5 \mathrm{~m}^{3} / \mathrm{jam}
\end{aligned}
$$

Sedangkan volume pemadatan pada zona 5 per 1 layer adalah,

$30 \mathrm{~m} \times 600 \mathrm{~m} \times 0,25=4500 \mathrm{~m}^{3}+$ penyusutan $10 \%$

$$
\begin{aligned}
& =4500 \mathrm{~m}^{3}+450 \\
& =4950 \mathrm{~m}^{3}
\end{aligned}
$$

Dengan banyaknya waktu yang diperlukan adalah

$$
\begin{aligned}
& =\frac{4950}{207,5} \\
& =23,8 \mathrm{jam} \sim 24 \mathrm{jam}
\end{aligned}
$$

Vibrator Roller dan Produktivitasnya

$$
\begin{aligned}
\mathrm{KP} & =\frac{1,60 \times 1,50 \times 0,25 \times 1000 \times 0,83}{8} \mathrm{~m}^{3} / \mathrm{jam} \\
& =\frac{498}{8} \\
& =62,25 \mathrm{~m}^{3} / \mathrm{jam}
\end{aligned}
$$

Sedangkan volume pemadatan pada zona 5 per 1 layer adalah,

$30 \mathrm{~m} \times 600 \mathrm{~m} \times 0,25=4500 \mathrm{~m}^{3}+$ penyusutan $10 \%$

$$
\begin{aligned}
& =4500 \mathrm{~m}^{3}+450 \\
& =4950 \mathrm{~m}^{3}
\end{aligned}
$$

Dengan banyaknya waktu yang diperlukan adalah

$$
\begin{aligned}
& =\frac{4950}{62,25} \\
& =79,5 \sim 80 \mathrm{jam}
\end{aligned}
$$




\section{Analisis Rencana Anggaran Biaya Penggunaan Alat Berat Sheep's Foot Roller Dan Vibrator Roller Dalam Pekerjaan Badan Jalan Pada Proyek Pembangunan Jalan Tol Medan- Kualanamu- Tebing Tinggi Seksi 3: Parbarakan - Lubuk Pakam Zona 5}

\section{Dump Truck dan Produktivitasnya}

Pada proyek pembangunan jalan tol Medan- Kualanamu- Tebing Tinggi seksi 3 : Perbarakan - Lubuk Pakam ini khususnya pada zona 5 dump truck digunakan untuk pengangkutan material tanah laterit/merah dari quarry menuju ke lokasi proyek. Pada proyek ini kapasitas angkut dump truck adalah $10 \mathrm{~m}^{3}$.

Dengan volume pemadatan pada zona 5 per 1 layer adalah ,

$30 \mathrm{~m} \times 600 \mathrm{~m} \times 0,25=4500 \mathrm{~m}^{3}+$ penyusutan $10 \%$

$$
\begin{aligned}
& =4500 \mathrm{~m}^{3}+450 \\
& =4950 \mathrm{~m}^{3}
\end{aligned}
$$

Jadi, banyaknya Dump Truck yang diperlukan untuk melakukan pemadatan dalam I layer adalah $4950: 10 \mathrm{~m}^{3}=495 \mathrm{DT}$.

\section{Motor Grader dan Produktivitasnya}

Kecepatan rata-rata motor grader adalah $3 \mathrm{~km} /$ jam dengan lebar efektif per pass 2,4 meter, sedangkan efisiensi kerja alat adalah 0,83 .

$$
\begin{aligned}
\text { Prod } & =1000 \times 3 \times 2,4 \times 0,83 \\
& =5976 \mathrm{~m}^{2} / \mathrm{jam}
\end{aligned}
$$

Sedangkan volume pemadatan pada zona 5 per 1 layer adalah,

$$
\begin{aligned}
30 \times 600 \mathrm{~m} \times 0,25 & =4500 \mathrm{~m}^{3}+\text { penyusutan } 10 \% \\
& =4500 \mathrm{~m}^{3}+450 \\
& =4950 \mathrm{~m}^{3}
\end{aligned}
$$

Dengan banyaknya waktu yang diperlukan adalah

$$
4950 \mathrm{~m}^{3}: 5976 \mathrm{~m}^{2}=0,82 \sim 1 \text { jam }
$$

\section{Tes Kepadatan Tanah}

Untuk mengetahui kadar air yang masih ada di dalam tanah timbunan maka perlu diadakan test untuk kepadatan tanah. Pada proyek ini tes kepadatan tanah dilakukan dengan cara tes Sand Cone dengan nilai kepadatan $95 \%$. Tes sand cone pada tanah dilakukan untuk menentukan kepadatan ditempat dari lapisan tanah atau perkerasan yang telah dipadatkan.

Hasil penelitian yang ditemukan pada lapangan setelah pemadatan menggunakan Vibrator Roller bahwa kadar air yang masih ada pada tanah timbunan adalah 18, $41 \%$ dengan berat jenis tanah pada saat pengujian dilakukan $1,62 \mathrm{gr} / \mathrm{cm}^{3}$.
Rencana Anggaran Biaya Pengoperasian Alat Berat Sheep Foot Roller dan Vibrator Roller

Pada proyek pembangunan jalan tol Medan- Kualanamu- Tebing Tinggi ini, pemadatan pada pekerjaan pembentukkan badan jalan menggunakan alat-alat berat yang dapat membantu prose pekerjaan pemadatan.Pada bagian ini penulis mengamati pada alat berat Sheep Foot Roller dan Vibrator Roller untuk memperhitungkan Rencana Anggaran Biaya pengoperasian alat berat Sheep Foot Roller dan Vibrator Roller.Pada bagian pekerjaan pemadatan badan jalan ini penulis mengamati pada zona 5 dengan panjang zona 5 sepanjang $600 \mathrm{~m}$ dan lebar 30 meter. Proyek pembangunan jalan tol Medan- KualanamuTebing Tinggi ini menggunakan alat berat Sheep

\begin{tabular}{|c|c|c|c|c|}
\hline No & $\begin{array}{l}\text { Jenis } \\
\text { pekerjaan } \\
\text { / Jenis } \\
\text { Biaya }\end{array}$ & Vol & $\begin{array}{l}\text { Harga } \\
\text { Satuan }\end{array}$ & Biaya \\
\hline 1 & $\begin{array}{l}\text { Biaya } \\
\text { penyewaan } \\
\text { alat }\end{array}$ & 1 jam & $\begin{array}{l}\text { Rp. } \\
81.600\end{array}$ & $\begin{array}{l}\text { Rp. } \\
81.600\end{array}$ \\
\hline 2 & $\begin{array}{l}\text { Biaya } \\
\text { Bahan } \\
\text { Bakar }\end{array}$ & $\begin{array}{l}12,5 / \\
\text { jam }\end{array}$ & $\begin{array}{l}\text { Rp. } \\
9.650\end{array}$ & $\begin{array}{l}\text { Rp. } \\
120.625\end{array}$ \\
\hline 3 & $\begin{array}{l}\text { Biaya Upah } \\
\text { kerja }\end{array}$ & $\begin{array}{l}1 \\
\text { hari }\end{array}$ & $\begin{array}{l}\text { Rp. } \\
150.000\end{array}$ & $\begin{array}{l}\text { Rp. } \\
150.000\end{array}$ \\
\hline 4 & $\begin{array}{l}\text { Biaya } \\
\text { pemakaian } \\
\text { minyak } \\
\text { pelumas }\end{array}$ & $\begin{array}{l}0,34 \\
\mathrm{gal} / \mathrm{j} \\
\mathrm{am}\end{array}$ & $\begin{array}{l}\text { Rp. } \\
75.407\end{array}$ & $\begin{array}{l}\text { Rp. } \\
25.638\end{array}$ \\
\hline 5 & $\begin{array}{l}\text { Biaya } \\
\text { Pemakaian } \\
\text { Gemuk }\end{array}$ & $\begin{array}{l}0,25 \\
\mathrm{~kg} / \mathrm{j} \\
\mathrm{am}\end{array}$ & $\begin{array}{l}\text { Rp. } \\
27.373\end{array}$ & $\begin{array}{l}\text { Rp. } \\
6.843\end{array}$ \\
\hline & Total & & \multicolumn{2}{|c|}{$\begin{aligned} & \operatorname{Rp} 384.606 / \mathrm{jam} \\
= & \operatorname{Rp} .384 .706 \times 24 \mathrm{jam} \\
= & \operatorname{Rp} 9.232 .944\end{aligned}$} \\
\hline
\end{tabular}
Foot Roller dengan merk Sakai type SV 515 TF dan Vibrator Roller dengan merk yang sama yaitu Sakai type SV 515 TF.

Rencana Anggaran Biaya Pengoperasian Alat Berat Sheep Foot Roller

Tabel 3. Biaya Operasional Total Per Jam Sheep Foot Roller

Jadi, Rencana Anggara Biaya pemakaian alat berat sheep foot roller pada proyek pembangunan jalan tol Medan- KualanamuTebing Tinggi Seksi 3 : Perbarakan- Lubuk Pakam, dimana panjang zona 5 adalah $600 \mathrm{~m}$ dan luas $30 \mathrm{~m}$ dengan lamanya produktivitas 
alat 24 jam memerlukan biaya pengoperasian alat berat sheep foot roller sebesar Rp 9. 232. 944 untuk menyelesaikan satu layer pemadatan pada pekerjaan pembentukkan badan jalan.

\section{Rencana Anggaran Biaya Pengoperasian Alat Berat Vibrator Roller}

Tabel 4. Biaya Operasional Total Per Jam Vibrator Roller

\begin{tabular}{|c|c|c|c|c|}
\hline No & $\begin{array}{l}\text { Jenis } \\
\text { pekerjaan } \\
\text { / Jenis } \\
\text { Biaya }\end{array}$ & Vol & $\begin{array}{l}\text { Harga } \\
\text { Satuan }\end{array}$ & Biaya \\
\hline 1 & $\begin{array}{l}\text { Biaya } \\
\text { penyewaan } \\
\text { alat }\end{array}$ & $1 \mathrm{jam}$ & $\begin{array}{l}\text { Rp. } \\
306.122\end{array}$ & $\begin{array}{l}\text { Rp. } \\
306.122\end{array}$ \\
\hline 2 & $\begin{array}{l}\text { Biaya } \\
\text { Bahan } \\
\text { Bakar }\end{array}$ & $\begin{array}{l}12,5 / \\
\text { jam }\end{array}$ & $\begin{array}{l}\text { Rp. } \\
9.650\end{array}$ & $\begin{array}{l}\text { Rp. } \\
120.625\end{array}$ \\
\hline 3 & $\begin{array}{l}\text { Biaya Upah } \\
\text { kerja }\end{array}$ & $\begin{array}{l}1 \\
\text { hari }\end{array}$ & $\begin{array}{l}\text { Rp. } \\
150.000\end{array}$ & $\begin{array}{l}\text { Rp. } \\
150.000\end{array}$ \\
\hline 4 & $\begin{array}{l}\text { Biaya } \\
\text { pemakaian } \\
\text { minyak } \\
\text { pelumas }\end{array}$ & $\begin{array}{l}0,34 \\
\mathrm{gal} / \mathrm{j} \\
\mathrm{am}\end{array}$ & $\begin{array}{l}\text { Rp. } \\
75.407\end{array}$ & $\begin{array}{l}\text { Rp. } \\
25.638\end{array}$ \\
\hline 5 & $\begin{array}{l}\text { Biaya } \\
\text { Pemakaian } \\
\text { Gemuk }\end{array}$ & $\begin{array}{l}0,25 \\
\mathrm{~kg} / \mathrm{j} \\
\mathrm{am}\end{array}$ & $\begin{array}{l}\text { Rp. } \\
27.373\end{array}$ & $\begin{array}{l}\text { Rp. } \\
6.843\end{array}$ \\
\hline & Total & & \multicolumn{2}{|c|}{$\begin{aligned} & \operatorname{Rp} 609.228 / \mathrm{jam} \\
= & \operatorname{Rp} 609.228 \times 80 \mathrm{jam} \\
= & \operatorname{Rp} 48.738 .240\end{aligned}$} \\
\hline
\end{tabular}

Jadi, Rencana Anggara Biaya pemakaian alat berat vibrator rollerpada proyek pembangunan jalan tol Medan- KualanamuTebing Tinggi Seksi 3 : Perbarakan- Lubuk Pakam, dimana panjang zona 5 adalah $600 \mathrm{~m}$ dan luas $30 \mathrm{~m}$ dengan lamanya produktivitas alat 80 jam memerlukan biaya pengoperasian alat berat vibrator rollersebesar Rp 48. 738. 240 untuk menyelesaikan satu layer pemadatan pada pekerjaan pembentukkan badan jalan.

\section{Rencana Anggaran Biaya Penggunaan Dump Truck dan Motor Grader}

Dari hasi produktivitas di atas diperoleh banyaknya dump truck yang diperlukan untuk menyelesaikan 1 layer pekerjaan pemadatan tanah adalah sebanyak 495 DT dengan kapasitas dump truck bermuatan $10 \mathrm{~m}^{3}$ sedangkan biaya upah sekali pengangkutan dump truck adalah Rp 450.000. Jadi biaya yang diperlukan adalah :

Biaya Dump Truck $=495$ DT $\times$ Rp 450.000

$$
=\operatorname{Rp} 222.750 .000
$$

Sedangkan untuk biaya penggunaan alat berat Motor Grader diketahui dari perhitungan produktivitas di atas banyaknya waktu yang diperlukan untuk menyelesaikan I layer pekerjaan pemadatan tanah adalah sebanyak 1 jam dengan biaya penggunaan motor grader per jam adalah Rp 81.600 . Jadi biaya yang diperlukan adalah :

$$
\begin{aligned}
\text { Biaya Motor Grader } & =1 \mathrm{jam} \times \operatorname{Rp} 81.600 \\
& =\operatorname{Rp} 81.600
\end{aligned}
$$

\section{Total Rencana Anggaran Biaya Penggunaan Alat Berat Sheep Foot}

\section{Roller,Vibrator Roller, Dump Truck, dan Motor Grader}

Tabel 5. Biaya Operasional Total Sheep Foot

\begin{tabular}{|c|c|c|c|c|c|}
\hline $\begin{array}{l}\mathrm{N} \\
\mathrm{o}\end{array}$ & $\begin{array}{l}\text { Alat } \\
\text { Berat }\end{array}$ & $\begin{array}{l}\text { Jam } \\
\text { oper } \\
\text { asi }\end{array}$ & $\begin{array}{l}\text { Kapasi } \\
\text { tas } \\
\text { Prod. } \\
\mathrm{m}^{3} / \mathrm{ja} \\
\mathrm{m}\end{array}$ & $\begin{array}{l}\text { Vol } \\
\mathrm{m}^{3}\end{array}$ & $\begin{array}{l}\text { Biaya yang } \\
\text { diperlukan }\end{array}$ \\
\hline 1 & $\begin{array}{l}\text { Sheep } \\
\text { Foot } \\
\text { Roller }\end{array}$ & $\begin{array}{l}24 \\
\text { jam }\end{array}$ & 207,5 & 4950 & Rp. $\quad 9.232 .944$ \\
\hline 2 & $\begin{array}{l}\text { Vibrato } \\
\text { r Roller }\end{array}$ & $\begin{array}{l}80 \\
\text { jam }\end{array}$ & 62,25 & 4950 & Rp. 48.738 .240 \\
\hline 3 & $\begin{array}{l}\text { Dump } \\
\text { Truck }\end{array}$ & $\begin{array}{l}495 \\
\text { DT }\end{array}$ & - & 4950 & Rp. 222.750 .000 \\
\hline 4 & $\begin{array}{l}\text { Motor } \\
\text { Grader }\end{array}$ & 1 jam & $5976 \mathrm{~m}^{3}$ & 4950 & Rp. 81.600 \\
\hline
\end{tabular}
Roller, Vibrator Roller, Dump Truck dan Motor Grader

Perhitungan Rencana Anggaran Biaya seperti yang diuraikan di atas, adalah untuk pemadatan tanah pada pekerjaan badan jalan untuk satu lapisan/ layer. Jadi proyek pembangunan jalan tol Medan- KualanamuTebing Tinggi Seksi 3 : Perbarakan- Lubuk Pakam, dalam pengoperasian alat berat Sheep Foot Roller dan Vibrator Roller pada proses pemadatan dalam pekerjaan pembentukkan badan jalan memerlukan biaya sebesar Rp 280.802.784 untuk satu lapisan/ layer.

\section{Kesimpulan dan Saran}

\subsection{Kesimpulan}

Berdasarkan hasil penelitian dan pembahasan yang telah penulis dapat dari proyek pembangunan jalan tol Medan Kualanamu - Tebing Tinggi Seksi3 


\section{Analisis Rencana Anggaran Biaya Penggunaan Alat Berat Sheep's Foot Roller Dan Vibrator Roller Dalam Pekerjaan Badan Jalan Pada Proyek Pembangunan Jalan Tol Medan- Kualanamu- Tebing Tinggi Seksi 3: Parbarakan - Lubuk Pakam Zona 5}

:Perbarakan - Lubuk Pakam adalah sebagai berikut :

1) Alat berat Sheep Foot Roller dan Vibrator Roller yang digunakan pada proyek pembangunan jalan tol MedanKualanamu- Tebing Tinggi Seksi3 :Perbarakan- Lubuk Pakam ini dalam keadaan baik.

2) Alat berat Sheep Foot Roller dan Vibrator Roller yang dipakai adalah merk Sakai dengan type SV 515 TF.

3) Produktivitas alat berat sheep foot roller yang telah diteliti dan dihitung yaitu pada pekerjaan timbunan dalam pembentukkan badan jalan adalah

$$
\frac{830}{4}=207,5 \mathrm{~m}^{3} / \mathrm{jam}, \quad \text { dengan }
$$

volume pemadatan pada zona 5 per 1 layer

adalah $30 \mathrm{~m} \times 600 \mathrm{~m} \times 025=4500 \mathrm{~m}^{3}+$ penyusutan $10 \%=4950 \mathrm{~m}^{3}$.

4) Waktu yang diperlukan sheep foot roller untuk menyelesaikan adalah

$$
\frac{4950}{207,5}=23,8 \sim 24 \text { jam. }
$$

5) Produktivitas alat berat vibrator roller yang telah diteliti dan dihitung yaitu pada pekerjaan timbunan dalam pembentukkan badan jalan adalah

$$
\frac{498}{8}=62,25 \mathrm{~m}^{3} / \text { jam, dengan }
$$

volume pemadatan pada zona 5 per 1 layer

$=30 \mathrm{~m} \times 600 \mathrm{~m} \times 0,25$

$=4500 \mathrm{~m}^{3}+$ penyusutan $10 \%$

$=4950 \mathrm{~m}^{3}$.

Waktu yang diperlukan vibrator roller untuk menyelesaikan adalah

$\underline{4950}=79,5 \sim 80 \mathrm{jam}$.

62,25

6) Rencana Anggaran Biaya pemakaian alat berat sheep foot roller untuk menyelesaikan zona 5 sepanjang 600 $\mathrm{m}$ dan lebar $30 \mathrm{~m}$ untuk 1 lapisan/layer adalah Rp 384. 706/ jam $\mathrm{x} 24$ jam waktu produktivitas $=\mathrm{Rp}$ 9.232.944.

7) Rencana Anggaran Biaya pemakaian alat berat vibrator roller untuk menyelesaikan zona 5 sepanjang 600 $\mathrm{m}$ danlebar $30 \mathrm{~m}$ untuk 1 lapisan/layer adalah Rp 609.228/ jam x 80 jam waktu produktivitas $=\mathrm{Rp}$ 48.738.240.

8) Rencana Anggaran Biaya pemakaian alat berat Dump Truck untuk menyelesaikan 1 lapisan/layer pemadatan adalah Rp 222.750.000.

9) Rencana Anggaran Biaya pemakaian alat berat Motor Grader untuk menyelesaikan 1 lapisan/layer pemadatan adalah $\mathrm{Rp} 81.600$.

10) Total Rencana Anggaran Biaya untuk penggunaan alat berat sheep foot roller vibrator roller, dump truck, dan motor grader pada pekerjaan timbunan dalam pembentukkan badan jalan adalah Rp 280. 802. 784.

11) Berhubung karena lapisan tanah yang akan dipadatkan adalah $75 \mathrm{~cm}$, maka pelaksanaan penimbunan dan pemadatan adalah 3 kali lapis/layer. Oleh karena itu total Rencana Anggaran Biaya untuk penggunaan sheep foot roller dan vibrator roller pada pekerjaan timbunan dan pembentukkan badan jalan adalah sebesar 3 x Rp 280.802.784 = Rp 842 . 408. 352 .

\subsection{Saran}

Pada proyek pembangunan jalan tol Medan- Kualanamu- Tebing Tinggi Seksi3 :Perbarakan- Lubuk Pakam ditemukan masalah/hambatan yang terjadi diluar dugaan maupun rencana sehingga mengakibatkan keterlambatan. Untuk itu pada kesempatan ini penulis memberikan saran yang mungkin bermanfaat bagi pihak yang bersangkutan :

1) Perlunya dilakukan pengecekan setiap melakukan pekerjaan maupun setelah selesai pekerjaan, agar mendapatkan hasil yang sesuai dengan yang direncanakan.

2) Perlunya peningkatan keamanan pada lokasi proyek agar bahan-bahan maupun peralatan pekerjaan yang berada pada pada lokasi proyek dapa tterjaga dengan baik.

3) Perlunya dilakukan pengecekkan pada pekerja yang berada pada lokasi proyek apabila ada yang belum 
menggunakan peralatan safety yang lengkap dan benar.

4) Perlunya mekanik yang stand by pada lokasi proyek apabila terjadi kerusakan pada alat berat.

5) Perlunya ketertiban dan kesadaran agar pekerja tetap mengutamakan K3.

\section{Daftar Pustaka}

Bestananda (2013) "Perhitungan Rencana Anggaran Biaya" Akses: 6 Mei 2016

(http://bestananda.blogspot.co.id/201 3/09/perhitungan-rencana-anggaranbiaya.html)

Ervianto, Wulfram I. (2004). " Teori- Aplikasi Manajemen Proyek Konstruksi" Yogyakarta: ANDI.

Peraturan Menteri Pekerjaan Umum No. 11/PRT/M/2013 tentang Pedoman Analisis Harga Satuan Pekerjaan Bidang Pekerjaan Umum.

Rostiyanti, Susi Fatena. (2002). " Alat Berat Untuk Proyek Konstruksi". Jakarta: Rineka Cipta.

Rochmanhadi. (1992). "Alat-alat Berat dan Penggunaannya" Semarang: YPBBU.

Wilopo, Djoko. (2011). " Metode Konstruksi dan Alat- Alat Berat". Jakarta: Universitas Indonesia (UI- Press). 